\title{
Multi-trophic interactions driving the transmission cycle of Borrelia afzelii between Ixodes ricinus and rodents: a review
}

Gilian van Duijvendijk ${ }^{1 *}$, Hein Sprong ${ }^{2}$ and Willem Takken ${ }^{3}$

\begin{abstract}
The tick Ixodes ricinus is the main vector of the spirochaete Borrelia burgdorferi sensu lato, the causal agent of Lyme borreliosis, in the western Palearctic. Rodents are the reservoir host of B. afzelii, which can be transmitted to I. ricinus larvae during a blood meal. The infected engorged larvae moult into infected nymphs, which can transmit the spirochaetes to rodents and humans. Interestingly, even though only about $1 \%$ of the larvae develop into a borreliae-infected nymph, the enzootic borreliae lifecycle can persist. The development from larva to infected nymph is a key aspect in this lifecycle, influencing the density of infected nymphs and thereby Lyme borreliosis risk. The density of infected nymphs varies temporally and geographically and is influenced by multi-trophic (tick-hostborreliae) interactions. For example, blood feeding success of ticks and spirochaete transmission success differ between rodent species and host-finding success appears to be affected by a B. afzelii infection in both the rodent and the tick. In this paper, we review the major interactions between I. ricinus, rodents and B. afzelii that influence this development, with the aim to elucidate the critical factors that determine the epidemiological risk of Lyme borreliosis. The effects of the tick, rodent and B. afzelii on larval host finding, larval blood feeding, spirochaete transmission from rodent to larva and development from larva to nymph are discussed. Nymphal host finding, nymphal blood feeding and spirochaete transmission from nymph to rodent are the final steps to complete the enzootic B. afzelii lifecycle and are included in the review. It is concluded that rodent density, rodent infection prevalence, and tick burden are the major factors affecting the development from larva to infected nymph and that these interact with each other. We suggest that the $B$. afzelii lifecycle is dependent on the aggregation of ticks among rodents, which is manipulated by the pathogen itself. Better understanding of the processes involved in the development and aggregation of ticks results in more precise estimates of the density of infected nymphs, and hence predictions of Lyme borreliosis risk.
\end{abstract}

Keywords: Ixodes ricinus, Borrelia burgdorferi, Trophic interactions, Ecology, Lifecycle, Apodemus, Myodes, Pathogen transmission

\section{Background}

Borrelia burgdorferi sensu lato (s.l.), a tick-borne pathogen, can cause Lyme borreliosis in humans [1]. Borrelia burgdorferi s.l. consists of several genospecies, of which B. afzelii, B. garinii and B. burgdorferi sensu stricto (s.s.) are the main cause of Lyme borreliosis in the western Palearctic $[2,3]$. Each of these genospecies is associated

\footnotetext{
* Correspondence: gilian.vanduijvendijk@wur.nl

'Laboratory of Entomology, Wageningen University and Research Centre,

Wageningen, The Netherlands

Full list of author information is available at the end of the article
}

with different enzootic lifecycles [4] and clinical manifestations [5]. Borrelia afzelii has been mostly associated with skin manifestations, whereas $B$. garinii is considered to be the most neurotropic and B. burgdorferi s.s. seems to be the most arthritogenic [6, 7]. Depending on the geographical location, the most common genospecies in I. ricinus are B. afzelii and B. garinii [8-12]. These genospecies are associated with different vertebrate host species. Borrelia afzelii is associated with rodents [4, 13-15], whereas B. garinii is associated with birds $[4,16]$. Because there is sufficient data on the 
interactions between rodents, ticks and borreliae (in contradiction to the data on birds) and because rodents are the main blood host for larvae [17], this review focusses on B. afzelii and rodents.

Ixodes ricinus is the principal vector of borreliae in the western Palearctic. This tick has three blood-feeding stages (larva, nymph and adult), which take a single blood meal before moulting to the next stage or laying eggs in the case of an adult female. Adult males do not feed. Larvae can become infected with $B$. afzelii via a blood meal from an infected rodent or via a blood meal from an uninfected host when feeding in close vicinity of a $B$. afzelii-infected tick, a co-feeding infection [18-21]. Rodents can become infected through the bite of an infected tick. It is generally believed that nymphs are responsible for infecting rodents because larvae are rarely infected and adults rarely feed on rodents. Nymphs are also the principle vectors that transmit borreliae to humans [22]. Therefore, the density of infected nymphs affects Lyme borreliosis risk, as was shown in the Nearctic [23]. The density of infected nymphs is determined by the density of nymphs * nymphal infection prevalence.

The interactions between ticks and rodents are complex and can influence pathogen transmission [24, 25]. The development from uninfected larva to infected nymph is a key aspect in the enzootic borreliae lifecycle. Density of larvae is about one order of magnitude higher than the density of nymphs $[26,27]$. Nymphal infection prevalence varies temporally and geographically, due to differences in climatic conditions [28], but is about $10 \%$ $[9,12,29]$. As a result, only about $1 \%$ of the I. ricinus larvae develops into a borreliae-infected nymph.

The aim of this review is to give an overview of the major multi-trophic (tick-rodent- $B$. afzelii) interactions that influence the development from an uninfected larva to an infected nymph. This development depends on the success of 1) host attachment of larvae, 2) blood feeding of larvae, 3) borreliae transmission from rodent to larvae, and 4) development from engorged larva to nymph (Fig. 1). Host attachment of nymphs, blood feeding of nymphs and borreliae transmission from nymph to rodent are the final steps to complete the enzootic $B$. afzelii lifecycle and therefore included. The review summarizes the current state of knowledge of the interactions between sub-adult I. ricinus, rodents and B. afzelii in the western Palearctic and how these interactions affect Lyme borreliosis risk.

\section{Host attachment}

Ixodes ricinus feeds on a variety of host species. Each instar of the tick climbs into the vegetation and enters a host-finding stage, termed questing, and senses hosts by $\mathrm{CO}_{2}$, host volatiles and vibrations [30-32]. Questing height was lower for larvae compared to nymphs [33]. During questing, water is lost from the tick, which can be reabsorbed when in the litter layer [34]. Attachment to a host is the first major step in the development from larva to nymph, but the chance that a larva encounters a rodent is unknown. Instead, tick burden will be used as a measurement of host-attachment success. Tick burden is determined by tick encounter rate, attachment success, grooming and tick feeding duration [35]. Factors affecting larval and nymphal host attachment are comparable and therefore combined in this paragraph.

\section{Host effects}

The chance that a questing larva encounters a host affects the density of nymphs and is influenced by the density and activity of hosts [36, 37], which vary between host species. Tick burdens vary between the most common rodent species in Europe; wood mouse (Apodemus sylvaticus), yellow-necked mouse (Apodemus flavicollis) and bank vole (Myodes glareolus). Larval tick burden is higher on wood mice than on bank voles [38-44], which may be caused by differences in ecological niche, activity, home range, grooming activity and immune response [45-47]. Bank voles have an innate and acquired tick resistance resulting in a lower tick attachment success compared to wood mice [45-51]. Ixodes ricinus can sense their host by smell [52] and may even be able to distinguish between host species as was shown in the Nearctic for I. scapularis [53, 54]. The genetic population structure of I. ricinus indicated that the species shows some host specialization [55]. The scale of this specialization is, however, unknown. Tick burden also varies within host species. In general there are many individuals with low tick burdens and few hosts with high tick burdens, feeding the majority of ticks $[40,56]$, following the $20 / 80$ rule $[57,58]$. This intra-species variation can be influenced by sex, age, body mass and activity of the host. In general, tick burden is higher on males compared to females, older rodents compared to younger rodents, heavy weight rodents compared to light weight rodents and active rodents compared to lessactive rodents [40, 59-64]. However, these relationships are complex, can be correlated to each other (e.g. males have a greater body weight than females) or interact with each other (tick burdens on females decreased with age whereas they increased on males) [56, 65].

Host preference of I. ricinus has not been tested experimentally, but there are examples of other tick species that show an intra-species host preference. Dermacentor variabilis preferred the odours from larger and male mice over smaller and female mice [66], I. arboricola preferred well developed bird nestlings over less developed nestlings [67], whereas I. hexagonus preferred sick hedgehogs over healthy ones [68]. Testosterone can also affect tick 


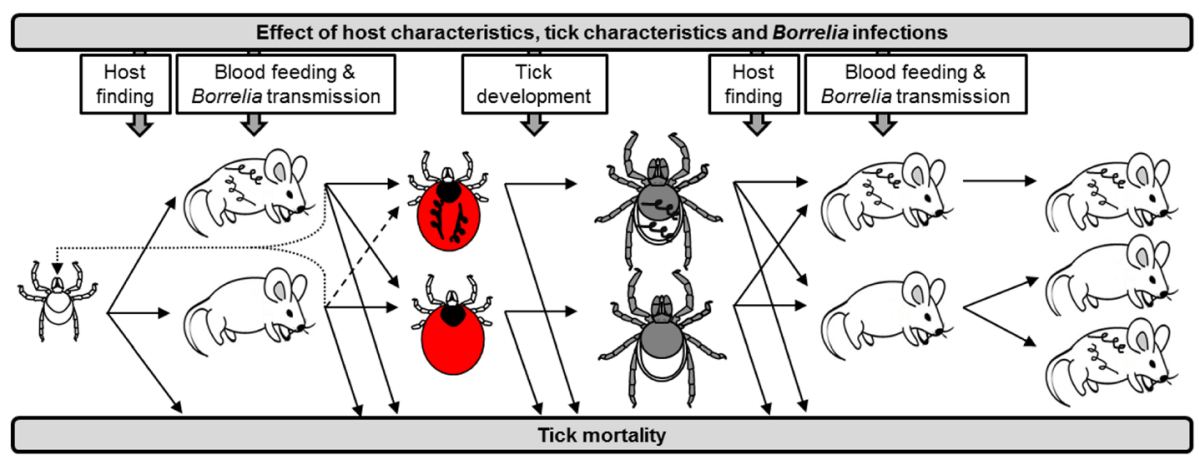

Fig. 1 From larva to infected nymph. Schematic overview of the steps involved in the development from an uninfected Ixodes ricinus larva to a $B$. afzelii-infected nymph and the transmission process of $B$. afzelii between rodent and tick. Dotted lines indicates continuation of questing after a partial blood meal, dashed line indicates co-feeding transmission

burden. It facilitates dominance in wild mice [69] and reduces innate and acquired resistance to ticks [47]. Testosterone levels also differed between rodent species and the level was 10 times higher in wood mice compared to bank voles [47]. High testosterone levels can also reduce tick feeding speed, as was found for ticks feeding on lizards [70].

\section{Tick effects}

Ectoparasites such as ticks affect the fitness of their hosts in various ways. For example, only $0.17 \%$ blood loss of gerbils (Gerbillus dasyurus) resulted in a $16 \%$ increased energy use [71]. This increased energy use should be compensated by an increased energy uptake and therefore host activity, increasing ectoparasite encounter rate. Feeding ticks can consume up to $65 \%$ of the blood from a rodent [40], affecting fitness and activity. Tick feeding can also cause erosion of the ear margin [72], reducing host fitness. Hosts with a larger home range have a higher reproductive success but may also have a higher tick burden, as was shown for I. scapularis and D. variabilis $[64,73]$. Larval tick burdens on rodents increased with increasing densities of questing larvae, but it was suggested that rodents can become saturated with larvae [65]. In addition, the heterogeneity in larval tick burdens on rodents can also be affected by the heterogeneous dispersal of larvae in the environment, increasing the chance of acquiring multiple larvae simultaneously.

\section{Borreliae pathogen effects}

There is abundant evidence that pathogens can influence their host and/or vector to enhance transmission $[74,75]$. Evidence of borreliae manipulating host attachment of ticks is, however, scarce. In the field, borreliae-infected rodents have higher tick burdens compared to borreliae-uninfected rodents [14, 44, 62].
Once infected, spirochaete load did not affect tick burden on rodents [76]. It is unclear whether borreliae can manipulate tick burden (e.g. due to a higher energy demand or altered odour of the rodent) or whether a high tick burden increased exposure risk to borreliae. Hosts with high nymphal tick burdens have a higher chance of becoming infected with borreliae and rodents infested with nymphs have higher larval tick burdens than rodents without nymphs [40,60,77]. A borreliae infection does not affect rodent survival [78, 79], but a specific borreliae antibody response altered foraging behaviour of white footed mice in the Nearctic $[80,81]$, which may increase tick encounter rate. There is also evidence that borreliae can influence host-tick contact rate when in the tick. A borreliae infection in adult female $I$. ricinus increased host finding efficacy [82]. In addition, borreliae-infected nymphs had higher energy reserves and spent more time questing for a host compared to borreliae-uninfected nymphs [33, 83-87]. These effects were influenced by B. burgdorferi s.l. genospecies [86]. However, all these results are from field-collected ticks and observed differences may, therefore, have been caused by characteristics of the host on which the ticks fed as larvae (e.g. species, tick burden, immune response). If, for example, tick burden positively affects blood meal size (see below), borreliae-infected ticks will have a higher fat content due to the higher tick burden of infected rodents, while this was not caused by the borreliae infection of the tick.

\section{Blood feeding}

Once a sub-adult tick has encountered a rodent, it needs to find a feeding site, bite the host and acquire a blood meal. It is generally assumed that each larva takes only one bloodmeal before moulting to a nymph. Factors affecting larval and nymphal blood feeding are comparable and therefore combined in this paragraph. 


\section{Host effects}

Blood feeding of I. ricinus is a complex process with major events occurring within the tick [45] and can be influenced by host species. Blood meal size and percentage of fully engorged ticks are larger for larvae feeding on Apodemus mice, which therefore moult into larger nymphs, compared to larvae that fed on bank voles [40, 41, 47, 88]. Exposure to tick saliva caused acquired tick resistance in bank voles, resulting in a decreased blood ingestion speed [47-50], whereas this was increased in yellow necked mice [48]. In addition, feeding duration had a positive effect on blood meal size in bank voles, but not in wood mice [41]. The effect of acquired tick resistance on tick feeding in I. ricinus was also found for rabbits [89].

\section{Tick effects}

Tick saliva has anti-haemostatic, anti-inflammatory, and immunosuppressive effects on the host's immune system, facilitating blood consumption of ticks [51, 90]. A larger tick burden results in more tick saliva and a higher immunosuppressive effect, which could therefore facilitate blood feeding of ticks. As a result, a high tick burden increased feeding success of I. ricinus feeding on wood mice and bank voles [47].

\section{Borreliae pathogen effects}

There are indications that aborreliae-infection results in an increased blood meal size of larvae. Infected engorged larvae collected from wood mice were heavier and moulted into larger nymphs compared to uninfected larvae [85]. The higher energy reserve of borreliae-infected nymphs (see above) is also likely to be a result of a larger blood meal during the larval stage. However, these differences could have been caused by a higher tick burden of infected hosts, affecting the immune response of the host (see above). In an artificial feeding system, blood meal size of nymphs decreased when fed Bartonella-infected blood compared to Bartonella-uninfected blood, whereas feeding duration was not affected [91].

\section{Development from engorged larva to nymph}

A larva that acquired a complete blood meal detaches from the host to digest its blood meal and moult into a nymph. When the larva acquired borreliae during this blood meal, it will emerge as an infected nymph after moulting.

\section{Host effects}

Moulting success from larva to nymph can be influenced by host species and was higher for larvae that naturally attached to field collected Apodemus mice compared to bank voles [13, 92], but the opposite happened for laboratory reared ticks [92]. After multiple infestations, moulting success remained stable in Apodemus mice but declined in bank voles; this effect was abolished, however, when testosterone levels were increased [47, 48]. A reduced moulting success was also found for I. trianguliceps feeding on bank voles [49] and may have been caused by a difference in blood meal success (see above) because partially-engorged larvae failed to moult [48].

\section{Tick effects}

Endosymbionts are widespread among arthropods [93, 94]. The effects of endosymbiots have not been investigated in I. ricinus. However, in the Nearctic they have been shown to influence tick fitness [95] and the colonization of borreliae in the tick [96]. The relationship between the tick microbiome and tick survival and borreliae transmission are far from understood [97] and has not been investigated in I. ricinus.

\section{Borreliae pathogen effects}

During moulting, borreliae spirochaetes survive in the midgut lumen of the tick and persistence until the next feeding is crucial for successful transmission [98, 99]. The interactions between the tick's defence mechanisms and borreliae during moulting have been reviewed [100]. It was shown that in the case of $I$. scapularis, even though borreliae load is reduced five fold during moulting and remained stable at $<300$ spirochaetes in the emerged nymph [101], spirochaete genetic population structure was not affected during moulting [102]. Whether a borreliae infection affects interstadial development from I. ricinus larva to nymph is unknown.

\section{Borrelia transmission from rodent to larva}

To maintain the enzootic borreliae lifecycle, rodents must feed both larvae and nymphs and an infection acquired by a larva must be transstadially transmitted during the moult to a nymph. Feeding larvae can also become borreliae-infected through co-feeding with an infected nymph on a host without a systemic infection [18-20]. However, because rodents are the main host used by larvae and can be systemically infected with borreliae, the effect of co-feeding transmission on the zoonotic life cycle of borreliae appears to be limited. The chance that a larva acquires borreliae from a host is determined by the borreliae prevalence in the host community, which is influenced by the probability that infected nymphs feed on the host, host susceptibility to the pathogen and the ability of the host to maintain the infection. The survival of borreliae within the host and tick, and transmission between them, are underpinned by molecular mechanisms, which have been reviewed $[35,103]$. 


\section{Host effects}

Not all host species used by I. ricinus are borreliae reservoirs and there is high variation in transmission efficiency among reservoir hosts. Rodents are associated with $B$. afzelii [4, 13-15]. Borrelia burgdorferi sensu stricto, $B$. bavariensis and B. spielmanii are also associated with rodents, but have a lower infection prevalence in questing nymphs [9, 104, 105]. Rodents can also be co-infected with multiple B. burgdorferi s.l. genospecies [15, 106, 107]. However, these different genospecies were not necessarily acquired through the bite of one nymph co-infected with multiple genospecies, but could be transmitted by multiple infected nymphs. Large mammals like roe deer and red deer are hosts for ticks, but incompetent for borreliae transmission, presumably because of anti-borreliae immune responses $[108,109]$. In the Nearctic, rodent infection rate (percentage of infected hosts) and host infectivity (percentage of uninfected larvae that acquire a borreliae infection during feeding on an infected host) are positively correlated and vary between host species [110]. Whether this is also true for the western Palearctic is not known. Rodent infection rate is lower in wood mice compared to bank voles and varies temporally and geographically $[13,15,44,111]$. Rodent infection rate can also differ between sexes and was higher in males compared to females [112], which was likely due to higher nymphal tick burdens on males, increasing exposure to borreliae. Infected rodents stay infective throughout their life resulting in a higher rodent infection rate of older rodents compared to younger rodents [113]. Borreliae infection prevalence of ticks fed on wild rodents was lower in April (1.2-10.5 \%) compared to June/July (15.1-17.5 \%) and did not increase until October [39], which is probably explained by a lower rodent infection rate caused by a lower exposure to borreliae-infected nymphs during winter compared to spring, summer and autumn.

Host infectivity is also influenced by host species and is lower in mice compared to voles [13, 39, 114, 115]. The differences between wood mice and bank voles can be caused by the number of borreliae-specific antibodies in the host, which correlated negatively to infectivity [116]. Even though infections were not lost, host infectivity can vary over time and decreases since inital infection of the rodents [112, 117]. A correlation between host body size versus infectivity and spirochaete burden in feeding ticks has not been tested for I. ricinus. However, this correlation was negative at host species level for I. scapularis [118]. These authors suggested that this was caused by a difference in time between inoculation and putative threshold for infectiousness.

\section{Tick effects}

The aggregation of ticks among hosts results in an increased borreliae transmission when larval and nymphal tick burdens are correlated. In addition, infectivity increased with successive larval infestations and larval tick burden [39, 113], increasing the contribution of these heavily infested individuals. Host infectivity of host associated B. burgdorferi s.l.-genospecies (B. garinii and $B$. valaisiana for birds) increased with successive infestations with field collected $I$. ricinus nymphs, whereas infectivity of genospecies associated with other hosts $(B$. afzelii for birds) decreased, suggesting a possible developed resistance [119]. The effect of tick burden on infectivity may be caused by the immunosuppressive effect of tick saliva on the rodent immune system [51, 90], resulting in an increased infectivity. However, infectivity of bank voles was reduced at sites with high tick densities [39]. Borreliae transmission from host to ticks increases with feeding time and started 2-8 h after tick attachment [120]. Borrelia afzelii has to survive the tick immune system during blood digestion, moulting and migration via the haemolymph to the salivary glands [121]. Nymphal infection prevalence had a positive effect on infection prevalence of larvae fed on rodents [39], most likely due to a higher exposure of rodents to infected nymphs.

\section{Borreliae pathogen effects}

Rodent infection rate varies between B. burgdorferi s.l. genospecies and is highest for $B$. afzelii, followed by $B$. burgdorferi s.s. and $B$. garinii $[15,44]$. Hosts can transmit multiple genospecies to feeding ticks [119], but host infection does not necessarily mean that the spirochaetes are transmitted to feeding ticks, as was shown for rodents infected with $B$. garinii in internal organs, which only transmitted B. burgdorferi s.s. to feeding larvae [4]. Spirochaete load of $B$. burgdorferi s.s. was higher when mice were co-infected with $B$. garinii, compared to an infection with only $B$. burgdorferi s.s., whereas the opposite happened for B. garinii [122], indicating interactions between the two genospecies while in the same host, which benefits B. burgdorferi s.s. Time until infectiousness also differs between genospecies; wood mice became infectious with $B$. afzelii in fewer days post infection and with a higher infectivity compared to $B$. burgdorferi s.s. [79, 117]. Borrelia burgdorferi s.s. was found only in rodents during tick activity, but not during winter [13], suggesting that these reservoir hosts are not a permanent reservoir for all genospecies and can lose infections, as was shown in the Nearctic for Peromyscus leucopus [123]. However, B. burgdorferi s.s. was also only found in mouse blood up to eight days after inoculation, whereas spirochaetemia lasted up to six weeks after inoculation [122]. Infectivity also differs between borreliae isolates, as was shown for B. afzelii [124]. The increased host's infectivity with time (see above) was also genospecies dependent and increased faster in B. afzelii 
compared to B. burgdorferi s.s. [120]. Borrelia afzelii (rodent associated) on the one hand and B. garinii and $B$. valaisiana (bird associated) on the other hand infect adult $I$. ricinus on a mutualistic exclusive way; they co-occurred less frequently than expected compared to co-infections with B. garinii and B. valaisiana [125]. Whether these different genospecies were transmitted during a single feed on one host or two feeds on separate hosts (as larva and nymph) is unclear, but it seems likely that $B$. afzelii in nymphs feeding on birds was negatively selected by host complement in the midgut of feeding ticks [126]. Strong genetic differentiation was observed between $B$. burgdorferi s.l. genotypes infecting different rodent species, suggesting host specificity of borreliae populations [127]. Spirochaete load at the feeding site positively influenced host infectivity $[76,102]$ and rodents with a high infectivity transmit more borreliae spirochaetes to larvae compared to the larvae fed on rodents with a lower infectivity [113]. However, even though spirochaete load was ten times higher in voles compared to mice, this did not result in a higher infectivity of voles compared to mice and this was probably due to a larger blood meal size on mice [76]. If a high spirochaete load in rodents results in a high spirochaete load in feeding ticks, infectivity from tick to host may also be enhanced. Spirochaete load in rodents and feeding ticks were, however, not correlated [76].

\section{Borrelia transmission from nymph to rodent}

Rodents acquire a borreliae infection through the bite of an infected tick and not via vertical transmission from female to offspring, as was shown for the Nearctic reservoir host Peromyscus leucopus [128, 129]. Ixodes ricinus larvae are rarely infected with B. burgdorferi s.l. [120] and adults rarely feed on rodents [44], suggesting that nymphs are responsible for transmitting borreliae to rodents. After a borreliae-infected nymph attaches to a host, the borreliae spirochaetes in the midgut multiply and migrate through the midgut wall via the haemolymph to the salivary glands, from which they may be inoculated with the tick saliva into the host $[130,131]$. Borreliae transmission from nymph to host is positively correlated with feeding duration of the tick and in general does not occur before $24 \mathrm{~h}$ of feeding $[132,133]$. However, borreliae can be transmitted as early as after 16-17 h of feeding [134], which may have been caused by a systemic borreliae infection in the tick [135]. Once spirochaetes have been inoculated into the host's skin, they remain at the inoculation site and disseminate after a few days, as was shown for B. burgdorferi s.s. in the Nearctic [136]. Borreliae have been detected in skin, blood, joints, spleen, heart, liver, urinary bladder, kidney and nervous system of vertebrate hosts [137-140].

\section{Host effects}

Not all host species are susceptible to each $B$. burgdorferi s.l. genospecies, due to differences in complementmediated sensitivity of the spirochaetes to host serum [126]. Borrelia afzelii is mainly associated with rodents [4, 14], B. garinii and B. valaisiana with birds [4, 16], $B$. lusitaniae with lizards [141] and B. spielmanii with dormice [142]. As a result, an infected tick that feeds on a host that is incompetent for the concerning genospecies appears to lose its infection [109, 143, 144]. However, this is not always the case, as was shown for B. afzelii in songbirds [119]. In the Nearctic, pre-exposure of rodents to I. scapularis reduced susceptibility to borreliae, irrespective of an acquired tick immunity $[145,146]$. This suggests that nymphal infection prevalence can influence rodent infection rate directly (a low nymphal infection prevalence reduces borreliae exposure to the host) or indirectly (a low nymphal infection prevalence reduces host susceptibility to borreliae) and that a high larval tick burden may reduce rodent infection rate by acquired immunity. This has not been investigated for $I$. ricinus, but indeed, rodent infection rate of white footed mice was ten times higher in periods with high risk of exposure to I. scapularis nymphs compared to a period of low risk [147]. Susceptibility to borreliae differed between bank vole individuals and was influenced by their genetic variation [112].

\section{Tick effects}

When borreliae-infected I. ricinus nymphs can feed to repletion, transmission success from nymph to host was almost $100 \%$ [134]. Nymphs do not need to have acquired the borreliae spirochaete(s) during a blood meal in the larval stage. It was shown for I. scapularis that nymphs can acquire borreliae during an interrupted feeding of $16 \mathrm{~h}$ and can infect another host after 3-5 days without first moulting to the next stage [148]. However, larvae that fed partially (18 h) on a borreliaeinfected host were not infectious during a second blood meal five weeks after the initial feeding, whereas borreliae were transmitted after they moulted into nymphs [149]. Partially-fed ticks can arise by tick immunity of the host [48]. In addition, grooming of the host or host mortality may also result in partially-fed ticks. However, whether this can also happen in I. ricinus and frequencies of naturally occurring partially-fed larvae and nymphs are unknown.

\section{Borreliae pathogen effects}

Ticks can be co-infected with more than one B. burgdorferi s.l. genospecies $[8,9,12,135,150]$, with up to $45 \%$ of infected ticks harbouring multiple genospecies [151]. Even though adult ticks have taken an additional blood meal, co-infection prevalence was not higher in adults 
compared to nymphs [12], which may be caused by the clearance of the genospecies acquired during the first blood meal by the ingestion of host complement during the second blood meal. Therefore, at least in the case of the nymphal stage, co-infections are likely to be acquired during one single blood meal from a co-infected host. The majority of co-infected nymphs is therefore coinfected with two genospecies that can co-occur in the same host [151, 152]. Spirochaete load in nymphs coinfected with genospecies that share vertebrate hosts was equal to or higher than the additive expectation, whereas this was lower for genospecies associated with different reservoir hosts [152]. Spirochaete load in infected ticks was higher for $B$. garinii and $B$. bavariensis compared to B. afzelii $[83,152]$. Even though all spirochaete clones present in the host were transmitted to the feeding larvae and survived moulting to the nymphal stage, only a small fraction of the spirochaetes in the tick's midgut are transmitted from nymph to host during feeding [102, 153]. Whether a high spirochaete load in infected nymphs results in a greater transmission success to a host during feeding is unknown. When injected intradermally, only 10 cultured borreliae spirochaetes were enough to infect a mouse [154].

\section{Conclusions}

Understanding the factors that affect the density of infected nymphs increases our knowledge on Lyme borreliosis risk. The development from questing I. ricinus larva to borreliae-infected nymph is affected by many biological and ecological factors. The existence of different B. burgdorferi s.l. genospecies and heterogeneity between and within genospecies makes the tick-rodentborreliae interactions complex. The development from larva to nymph, regardless of a borreliae infection, affects nymphal density and appears to be successful in only $10 \%$ of the time [155]. The chance that a larva encounters a rodent affects the density of nymphs and is influenced by rodent density, which differs between rodent species and varies spatially and temporally $[39,63]$. Even though it is a major step in the development, there is no data of the chance that a larva actually encounters a rodent or any other host. Host encounter rate may not be fully dependent on external factors but may be affected by the tick too, e.g. when larvae are attracted to a rodent trail. Nymphs for example, are attracted to perches that have been scented with rodent odour [52]. It was shown that ticks prefer odours from certain hosts over others. However, it is unknown if questing larvae can afford to reject a non-preferred host, risking the possibility of not acquiring any blood meal and starving to death.

Rodents with high larval tick burdens, which are major contributors to the density of nymphs, have in general also higher nymphal tick burdens, making them more likely to be infected with borreliae. As a result, these rodents are even larger contributors to the density of infected nymphs. We hypothesize that this aggregation increases nymphal infection prevalence and that this aggregation is therefore necessary for the maintenance of the enzootic borreliae lifecycle. There is some evidence that the aggregation of ticks can be caused by borreliae $[14,44]$. Therefore, the chance that a larva acquires a blood meal from an infected rodent may not solely be the effect of the density of infected rodents, e.g. when borreliae-infected rodents are more active than uninfected rodents, or when questing larvae prefer-the odours from-borreliae-infected rodents, the chance of acquiring a borreliae infection is greater than the effect of rodent density alone. Even though the only experimental study conducted on this subject showed no effect of a borreliae infection in rodents on tick attraction [52], there are many examples of parasites manipulating their hosts [74, 75]. Therefore, understanding rodent or tick manipulation by borreliae requires more experiments with experimentally infected rodents and ticks to exclude biases from differences in rodent characteristics on physiological or behavioural differences between infected and uninfected rodents and ticks.

The borreliae lifecycle does not only benefit from aggregation of larvae on (borreliae-infected) rodents, but also from the successful development from larvae to nymph and the chance that aborreliae-infected nymph encounters a (borreliae-uninfected) rodent. Whether borreliae can affect interstadial tick development (e.g. moulting success) is unknown and requires more research to overcome a bias in the effect of the $90 \%$ mortality during development from larva to nymph [155].

Tick survival, rodent density, rodent infection rate and host infectivity are major factors affecting the borreliae lifecycle, whereas only the first two directly affect the tick lifecycle. These factors also interact with each other, e.g. even though infection rate and infectivity of bank voles was higher, the higher tick burden on wood mice and moulting success of ticks fed on wood mice made wood mice more important contributors to the density of infected nymphs [13]. The tick lifecycle clearly benefits from a high density of nymphs, whereas the borreliae lifecycle benefits from a high nymphal infection prevalence. However, the borreliae lifecycle also benefits from a high density of nymphs, when this will lead to a higher density of larvae and therefore a higher chance of borreliae transmission from rodent to tick and vice versa. There is evidence that borreliae can affect tick survival, increasing the density of nymphs and therefore enhancing its own lifecycle. Therefore, in addition, the tick lifecycle also benefits from a high nymphal infection prevalence. 
More knowledge on these multi-trophic interactions helps to obtain better estimates of the Lyme borreliosis risk. This review showed the various factors that contribute to the density of infected nymphs, and how they interact. These results, together with the effect of abiotic factors, could be mathematically modelled to determine the key processes that determine the density of infected nymphs, and thereby Lyme borreliosis risk.

\section{Competing interest}

The authors declare that they have no competing interests.

\section{Authors' contributions}

GD, HS and WT discussed the contents of the review. GD drafted the manuscript. HS and WT revised the manuscript. All authors contributed to the design of the study and read and approved the final manuscript.

\section{Acknowledgements}

We thank two anonymous reviewers for their comments on an earlier version of the manuscript. The study was funded by a grant from the Ministry of Health, Welfare and Sport, The Netherlands.

\section{Author details}

'Laboratory of Entomology, Wageningen University and Research Centre, Wageningen, The Netherlands. ${ }^{2}$ Laboratory for Zoonosis and Environmental Microbiology, National Institute for Public Health and Environment (RIVM), Bilthoven, The Netherlands. ${ }^{3}$ Laboratory of Entomology, Wageningen University and Research Centre, Wageningen, The Netherlands.

Received: 9 October 2015 Accepted: 10 December 2015 Published online: 18 December 2015

\section{References}

1. Medlock JM, Hansford KM, Bormane A, Derdakova M, Estrada-Pena A, George JC, Golovljova I, Jaenson TG, Jensen JK, Jensen PM, et al. Driving forces for changes in geographical distribution of Ixodes ricinus ticks in Europe. Parasit Vectors. 2013;6(1):1.

2. Gray JS. The ecology of ticks transmitting Lyme borreliosis. Exp Appl Acarol. 1998;22(5):249-58.

3. Grubhoffer L, Golovchenko M, Vancová M, Zacharovová-Slavičková K, Rudenko N, Oliver Jr JH. Lyme borreliosis: Insights into tick-/host-borrelia relations. Folia Parasitol. 2005;52(4):279-94.

4. Kurtenbach K, Peacey M, Rijpkema SG, Hoodless AN, Nuttall PA, Randolph SE. Differential transmission of the genospecies of Borrelia burgdorferi sensu lato by game birds and small rodents in England. Appl Environ Microbiol. 1998;64(4):1169-74.

5. Nau R, Christen HJ, Eiffert H. Lyme disease-current state of knowledge. Dtsch Arztebl Int. 2009;106(5):72-81.

6. Stanek G, Wormser GP, Gray J, Strle F. Lyme borreliosis. Lancet. 2012; 379(9814):461-73.

7. Strle F, Stanek G. Clinical manifestations and diagnosis of lyme borreliosis. Curr Probl Dermatol. 2009;37:51-110.

8. Wilhelmsson P, Lindblom P, Fryland L, Ernerudh J, Forsberg P, Lindgren PE Prevalence, diversity, and load of Borrelia species in ticks that have fed on humans in regions of Sweden and angstrom land islands, Finland with different Lyme borreliosis incidences. Plos One. 2013;8(11):e81433.

9. Gassner F, Van Vliet AJH, Burgers SLGE, Jacobs F, Verbaarschot P, Hovius EKE, et al. Geographic and temporal variations in population dynamics of ixodes ricinus and associated borrelia infections in the Netherlands. Vector Borne Zoonotic Dis. 2011;11(5):523-32.

10. Tappe J, Jordan D, Janecek E, Fingerle V, Strube C. Revisited: Borrelia burgdorferi sensu lato infections in hard ticks (Ixodes ricinus) in the city of Hanover (Germany). Parasit Vectors. 2014;7(1):441.

11. Cadenas FM, Rais O, Humair PF, Douet V, Moret J, Gern L. Identification of host bloodmeal source and Borrelia burgdorferi sensu lato in field-collected Ixodes ricinus ticks in chaumont (Switzerland). J Med Entomol. 2007:44(6): 1109-17.
12. Rauter $C$, Hartung T. Prevalence of Borrelia burgdorferi sensu lato genospecies in Ixodes ricinus ticks in Europe: a metaanalysis. Appl Environ Microbiol. 2005; 71(11):7203-16.

13. Humair PF, Rais O, Gern L. Transmission of Borrelia afzelii from Apodemus mice and Clethrionomys voles to Ixodes ricinus ticks: differential transmission pattern and overwintering maintenance. Parasitology. 1999;1 18(1):33-42.

14. Hanincova K, Schäfer SM, Etti S, Sewell HS, Taragelová V, Ziak D, et al. Association of Borrelia afzelii with rodents in Europe. Parasitology. 2003;126(1):11-20.

15. Kybicova K, Kurzova Z, Hulinska D. Molecular and serological evidence of Borrelia burgdorferi sensu lato in wild rodents in the Czech Republic. Vector Borne Zoonotic Dis. 2008;8(5):645-52.

16. Hanincová K, Taragelová V, Koci J, Schäfer SM, Hails R, Ullmann AJ, et al. Association of Borrelia garinii and B. valaisiana with songbirds in Slovakia. Appl Environ Microbiol. 2003;69(5):2825-30.

17. Matuschka FR, Fischer P, Musgrave K, Richter D, Spielman A. Hosts on which nymphal Ixodes ricinus most abundantly feed. Am J Trop Med Hyg. 1991; 44(1):100-7.

18. Randolph SE, Gern L, Nuttall PA. Co-feeding ticks: Epidemiological significance for tick-borne pathogen transmission. Parasitol Today. 1996; 12(12):472-9.

19. Gern L, Rais O. Efficient transmission of Borrelia burgdorferi between cofeeding Ixodes ricinus ticks (Acari: Ixodidae). J Med Entomol. 1996;33(1):189-92.

20. Randolph SE. Transmission of tick-borne pathogens between co-feeding ticks: Milan Labuda's enduring paradigm. Ticks Tick Borne Dis. 2011;2(4): 179-82.

21. Voordouw MJ. Co-feeding transmission in Lyme disease pathogens. Parasitology. 2015;142(2):290-302.

22. Matuschka FR, Fischer P, Heiler M, Blumcke S, Spielman A. Stage-associated risk of transmission of the Lyme disease spirochete by European Ixodes ticks. Parasitol Res. 1992;78(8):695-8.

23. Stafford lii KC, Cartter ML, Magnarelli LA, Ertel SH, Mshar PA. Temporal correlations between tick abundance and prevalence of ticks infected with Borrelia burgdorferi and increasing incidence of Lyme disease. J Clin Microbiol. 1998;36(5):1240-4.

24. Randolph SE, Nuttall PA. Nearly right or precisely wrong - Natural versus laboratory studies of vector-borne diseases. Parasitol Today. 1994;10(12):458-62.

25. Ribeiro JM. Role of saliva in tick/host interactions. Exp Appl Acarol. 1989;7(1): 15-20.

26. Barandika JF, Hurtado A, Juste RA, García-Pérez AL. Seasonal dynamics of Ixodes ricinus in a 3-year period in northern Spain: First survey on the presence of tick-borne encephalitis virus. Vector Borne Zoonotic Dis. 2010; 10(10):1027-35.

27. Barandika JF, Berriatua E, Barral M, Juste RA, Anda P, García-Pérez AL. Risk factors associated with ixodid tick species distributions in the Basque region in Spain. Med Vet Entomol. 2006:20(2):177-88.

28. Estrada-Pena A, Ortega C, Sanchez N, Desimone L, Sudre B, Suk JE, et al. Correlation of Borrelia burgdorferi sensu lato prevalence in questing Ixodes ricinus ticks with specific abiotic traits in the western palearctic. Appl Environ Microbiol. 2011;77(11):3838-45.

29. Coipan EC, Jahfari S, Fonville M, Maassen CB, van der Giessen J, Takken W, et al. Spatiotemporal dynamics of emerging pathogens in questing Ixodes ricinus. Front Cell Infect Microbiol. 2013;3:36.

30. Gherman CM, Mihalca AD, Dumitrache MO, Györke A, Oroian I, Sandor M, et al. CO 2 flagging - An improved method for the collection of questing ticks. Parasit Vectors. 2012;5(1):125.

31. Lees AD. The sensory physiology of the sheep tick, Ixodes ricinus L. J Exp Biol. 1948;25(2):145-207.

32. Osterkamp J, Wahl U, Schmalfuss G, Haas W. Host-odour recognition in two tick species is coded in a blend of vertebrate volatiles. J Comp Physiol. 1999;185(1):59-67.

33. Mejlon HA, Jaenson TGT. Questing behaviour of Ixodes ricinus ticks (Acari: Ixodidae). Exp Appl Acarol. 1997;21(12):747-54.

34. Lees AD. The water balance in Ixodes ricinus $L$. and certain other species of ticks. Parasitology. 1946;37:1-20.

35. Mannelli A, Bertolotti L, Gern L, Gray J. Ecology of Borrelia burgdorferi sensu lato in Europe: transmission dynamics in multi-host systems, influence of molecular processes and effects of climate change. FEMS Microbiol Rev. 2012;36(4):837-61.

36. Jones CG, Ostfeld RS, Richard MP, Schauber EM, Wolff JO. Chain reactions linking acorns to gypsy moth outbreaks and Lyme disease risk. Science. 1998;279(5353):1023-6. 
37. Rosa R, Pugliese A, Ghosh M, Perkins SE, Rizzoli A. Temporal variation of Ixodes ricinus intensity on the rodent host Apodemus flavicollis in relation to local climate and host dynamics. Vector Borne Zoonotic Dis. 2007;7(3): 285-95.

38. Humair PF, Turrian N, Aeschlimann A, Gern L. Borrelia-burgdorferi in a focus of Lyme borreliosis - Epizootiologic contribution of small mammals. Folia Parasitol. 1993;40(1):65-70.

39. Kurtenbach K, Kampen H, Dizij A, Arndt S, Seitz HM, Schaible UE, et al. Infestation of rodents with larval Ixodes ricinus (Acari: Ixodidae) is an important factor in the transmission cycle of Borrelia burgdorferi s.l. in German woodlands. J Med Entomol. 1995;32(6):807-17.

40. Talleklint $L$, Jaenson TG. Infestation of mammals by Ixodes ricinus ticks (Acari: Ixodidae) in south-central Sweden. Exp Appl Acarol. 1997;21(12): 755-71.

41. Nilsson A, Lundqvist L. Host selection and movements of Ixodes ricinus (Acari) larvae on small mammals. Oikos. 1978;31(3):313-22.

42. Boyard C, Vourc'h G, Barnouin J. The relationships between Ixodes ricinus and small mammal species at the woodland-pasture interface. Exp Appl Acarol. 2008;44(1):61-76

43. Gray JS, Kirstein F, Robertson JN, Stein J, Kahl O. Borrelia burgdorferi sensu lato in Ixodes ricinus ticks and rodents in a recreational park in southwestern Ireland. Exp Appl Acarol. 1999;23(9):717-29.

44. Gassner F, Takken W, Plas CL, Kastelein P, Hoetmer AJ, Holdinga M, et al. Rodent species as natural reservoirs of Borrelia burgdorferi sensu lato in different habitats of Ixodes ricinus in The Netherlands. Ticks Tick Borne Dis. 2013:4(5):452-8

45. Kaufman WR. Tick-host interaction - a synthesis of current concepts. Parasitol Today. 1989;5(2):47-56.

46. Wikel SK. Host immunity to ticks. Annu Rev Entomol. 1996:41:1-22.

47. Hughes VL, Randolph SE. Testosterone depresses innate and acquired resistance to ticks in natural rodent hosts: a force for aggregated distributions of parasites. J Parasitol. 2001;87(1):49-54.

48. Dizij A, Kurtenbach K. Clethrionomys glareolus, but not Apodemus flavicollis acquires resistance to Ixodes ricinus $L$., the main European vector of Borrelia burgdorferi. Parasite Immunol. 1995;17(4):177-83.

49. Randolph SE. Density-dependent acquired resistance to ticks in natural hosts, independent of concurrent infection with Babesia microti. Parasitology. 1994;108(4):413-9.

50. Randolph SE. Population regulation in ticks: The role of acquired resistance in natural and unnatural hosts. Parasitology. 1979;79(1):141-56.

51. Wikel SK. Tick modulation of host immunity: an important factor in pathogen transmission. Int J Parasitol. 1999;29(6):851-9.

52. Berret J, Voordouw MJ. Lyme disease bacterium does not affect attraction to rodent odour in the tick vector. Parasit Vectors. 2015;8(1):249.

53. Shaw MT, Keesing F, McGrail R, Ostfeld RS. Factors influencing the distribution of larval blacklegged ticks on rodent hosts. Am J Trop Med Hyg. 2003:68(4):447-52.

54. James AM, Oliver Jr JH. Feeding and host preference of immature Ixodes dammini, I. scapularis, and I. pacificus (Acari: Ixodidae). J Med Entomol. 1990; 27(3):324-30.

55. Kempf F, De Meeus T, Vaumourin E, Noel V, Taragel'ova V, Plantard O, et al. Host races in Ixodes ricinus, the European vector of Lyme borreliosis. Infect Genet Evol. 2011:11(8):2043-8.

56. Heylen D, Adriaensen F, Van Dongen S, Sprong H, Matthysen E. Ecological factors that determine Ixodes ricinus tick burdens in the great tit (Parus major), an avian reservoir of Borrelia burgdorferi s.I. Int J Parasitol. 2013;43(8): 603-11.

57. Woolhouse MEJ, Dye C, Etard JF, Smith T, Charlwood JD, Garnett GP, et al. Heterogeneities in the transmission of infectious agents: Implications for the design of control programs. Proc Natl Acad Sci U S A. 1997;94(1):338-42.

58. Perkins SE, Cattadori IM, Tagliapietra V, Rizzoli AP, Hudson PJ. Empirical evidence for key hosts in persistence of a tick-borne disease. Int J Parasitol. 2003;33(9):909-17.

59. Harrison A, Scantlebury M, Montgomery WI. Body mass and sex-biased parasitism in wood mice Apodemus sylvaticus. Oikos. 2010;119(7): 1099-104.

60. Craine NG, Randolph SE, Nuttall PA. Seasonal variation in the role of grey squirrels as hosts of Ixodes ricinus, the tick vector of the Lyme disease spirochaete, in a British woodland. Folia Parasitol. 1995;42(1):73-80.

61. Pisanu B, Marsot M, Marmet J, Chapuis JL, Reale D, Vourc'h G. Introduced Siberian chipmunks are more heavily infested by ixodid ticks than are native bank voles in a suburban forest in France. Int $J$ Parasitol. 2010;40(11):1277-83.

62. Taylor KR, Takano A, Konnai S, Shimozuru M, Kawabata H, Tsubota T. Differential tick burdens may explain differential Borrelia afzelii and Borrelia garinii infection rates among four, wild, rodent species in Hokkaido Japan. J Vet Med Sci. 2013;75(6):785-90.

63. De Boer R, Hovius KE, Nohlmans MK, Gray JS. The woodmouse (Apodemus sylvaticus) as a reservoir of tick-transmitted spirochetes (Borrelia burgdorferi) in The Netherlands. Zentralbl Bakteriol. 1993;279(3):404-16.

64. Sonenshine DE, Stout J. Tick burdens in relation to spacing and range of hosts in Dermacentor variabilis. J Med Entomol. 1968;5(1):49-52.

65. Brunner JL, Ostfeld RS. Multiple causes of variable tick burdens on smallmammal hosts. Ecology. 2008;89(8):2259-72.

66. Dallas T, Fore S. Chemical attraction of Dermacentor variabilis ticks parasitic to Peromyscus leucopus based on host body mass and sex. Exp Appl Acarol. 2013;61(2):243-50.

67. Heylen DJA, Matthysen E. Experimental evidence for host preference in a tick parasitizing songbird nestlings. Oikos. 2011;120(8):1209-16.

68. Bunnell T, Hanisch $K$, Hardege JD, Breithaupt T. The fecal odor of sick hedgehogs (Erinaceus europaeus) mediates olfactory attraction of the tick Ixodes hexagonus. J Chem Ecol. 2011:37(4):340-7.

69. Zielinski WJ, Vandenbergh JG. Testosterone and competitive ability in male house mice, Mus musculus - Laboratory and field studies. Anim Behav. 1993;45(5):873-91.

70. Pollock NB, Vredevoe LK, Taylor EN. How do host sex and reproductive state affect host preference and feeding duration of ticks? Parasitol Res. 2012; 111(2):897-907.

71. Khokhlova IS, Krasnov BR, Kam M, Burdelova NI, Degen AA. Energy cost of ectoparasitism: the flea Xenopsylla ramesis on the desert gerbil Gerbillus dasyurus. J Zool. 2002:258(3):349-54.

72. Harris PD, Paziewska A, Zwolińska L, Siński E. Seasonality of the ectoparasite community of woodland rodents in a Mazurian Forest. Poland Wiad Parazytol. 2009;55(4):377-88.

73. Devevey $G$, Brisson D. The effect of spatial heterogenity on the aggregation of ticks on white-footed mice. Parasitology. 2012;139(7):915-25.

74. Moore J. The behavior of parasitized animals. Bioscience. 1995;45(2):89-96.

75. Lefèvre T, Thomas F. Behind the scene, something else is pulling the strings: Emphasizing parasitic manipulation in vector-borne diseases. Infect Genet Evol. 2008;8(4):504-19.

76. Raberg L. Infection intensity and infectivity of the tick-borne pathogen Borrelia afzelii. J Evol Biol. 2012;25(7):1448-53.

77. Bown KJ, Lambin X, Telford GR, Ogden NH, Telfer S, Woldehiwet Z, et al. Relative importance of Ixodes ricinus and Ixodes trianguliceps as vectors for Anaplasma phagocytophilum and Babesia microti in field vole (Microtus agrestis) populations. Appl Environ Microbiol. 2008; 74(23):7118-25

78. Voordouw MJ, Lachish S, Dolan MC. The lyme disease pathogen has no effect on the survival of its rodent reservoir host. PLoS One. 2015;10(2): e0118265.

79. Radolf JD, Caimano MJ, Stevenson B, Hu LT. Of ticks, mice and men: understanding the dual-host lifestyle of Lyme disease spirochaetes. Nat Rev Microbiol. 2012;10(2):87-99.

80. Schwanz LE, Brisson D, Gomes-Solecki M, Ostfeld RS. Linking disease and community ecology through behavioural indicators: immunochallenge of white-footed mice and its ecological impacts. J Anim Ecol. 2011; 80(1):204-14

81. Schwanz LE, Previtali MA, Gomes-Solecki M, Brisson D, Ostfeld RS. Immunochallenge reduces risk sensitivity during foraging in whitefooted mice. Anim Behav. 2012;83(1):155-61.

82. Faulde MK, Robbins RG. Tick infestation risk and Borrelia burgdorferi s.l. infection-induced increase in host-finding efficacy of female Ixodes ricinus under natural conditions. Exp Appl Acarol. 2008:44(2):137-45.

83. Herrmann C, Gern L. Do the level of energy reserves, hydration status and Borrelia infection influence walking by Ixodes ricinus (Acari: Ixodidae) ticks? Parasitology. 2012;139(3):330-7

84. Herrmann C, Voordouw MJ, Gern L. Ixodes ricinus ticks infected with the causative agent of Lyme disease, Borrelia burgdorferi sensu lato, have higher energy reserves. Int J Parasitol. 2013;43(6):477-83.

85. Gassner F. Tick Tactics - Interactions between habitat characteristics, hosts and microorganisms in relation to the biology of the sheep tick Ixodes ricinus. Wageningen: Wageningen University; 2010. 
86. Herrmann C, Gern L. Survival of Ixodes ricinus (Acari: Ixodidae) under challenging conditions of temperature and humidity is influenced by Borrelia burgdorferi sensu lato infection. J Med Entomol. 2010;47(6):1196-204.

87. Herrmann C, Gern L. Search for blood or water is influenced by Borrelia burgdorferi in Ixodes ricinus. Parasit Vectors. 2015;8:6.

88. Matuschka FR, Fischer P, Heiler M, Richter D, Spielman A. Capacity of European animals as reservoir hosts for the Lyme disease spirochete. J Infect Dis. 1992;165(3):479-83.

89. Alani AJ, Herbert IV. Effect of host resistance on the feeding and reproductive performance of Haemaphysalis punctata and Ixodes ricinus ticks. Res Vet Sci. 1987;42(2):238-43.

90. Gillespie RD, Mbow ML, Titus RG. The immunomodulatory factors of bloodfeeding arthropod saliva. Parasite Immunol. 2000;22(7):319-31.

91. Liu XY, Cote M, Paul RE, Bonnet SI. Impact of feeding system and infection status of the blood meal on Ixodes ricinus feeding. Ticks Tick Borne Dis. 2014;5(3):323-8.

92. Burri C, Schumann O, Schumann C, Gern L. Are Apodemus spp. mice and Myodes glareolus reservoirs for Borrelia miyamotoi, Candidatus Neoehrlichia mikurensis, Rickettsia helvetica, R. monacensis and Anaplasma phagocytophilum? Ticks Tick Borne Dis. 2014;5(3):245-51.

93. Zug R, Hammerstein P. Bad guys turned nice? A critical assessment of Wolbachia mutualisms in arthropod hosts. Biol Rev. 2015;90(1):89-111.

94. Dennison NJ, Jupatanakul N, Dimopoulos G. The mosquito microbiota influences vector competence for human pathogens. Curr Opin Insect Sci. 2014:3:6-13.

95. Zhong J, Jasinskas A, Barbour AG. Antibiotic Treatment of the Tick Vector Amblyomma americanum Reduced Reproductive Fitness. PLoS One. 2007; 2(5):e405.

96. Narasimhan S, Rajeevan N, Liu L, Zhao YO, Heisig J, Pan J, et al. Gut microbiota of the tick vector Ixodes scapularis modulate colonization of the Lyme disease spirochete. Cell Host Microbe. 2014;15(1):58-71.

97. Narasimhan S, Fikrig E: Tick microbiome: The force within. Trends Parasitol 2015

98. Burgdorfer W, Barbour AG, Hayes SF, Benach JL, Grunwaldt E, Davis JP. Lyme disease - A tick-borne spirochetosis? Science. 1982;216(4552):1317-9.

99. Burgdorfer W. Discovery of the Lyme disease spirochete and its relation to tick vectors. Yale J Biol Med. 1984;57(4):515-20.

100. Hajdusek O, Sima R, Ayllon N, Jalovecka M, Perner J, de la Fuente J, et al. Interaction of the tick immune system with transmitted pathogens. Front Cell Infect Microbiol. 2013;3:26.

101. Piesman J, Oliver JR, Sinsky RJ. Growth kinetics of the Lyme disease spirochete (Borrelia burgdorferi) in vector ticks (Ixodes dammini). Am J Trop Med Hyg. 1990:42(4):352-7

102. Rego RO, Bestor A, Stefka J, Rosa PA. Population bottlenecks during the infectious cycle of the Lyme disease spirochete Borrelia burgdorferi. PLoS One. 2014;9(6):e101009.

103. Schuijt TJ, Hovius JW, van der Poll T, van Dam AP, Fikrig E. Lyme borreliosis vaccination: The facts, the challenge, the future. Trends Parasitol. 2011;27(1): 40-7.

104. Margos G, Vollmer SA, Cornet M, Garnier M, Fingerle V, Wilske B, et al. A new Borrelia species defined by multilocus sequence analysis of housekeeping genes. Appl Environ Microbiol. 2009;75(16):5410-6.

105. Richter D, Schlee DB, Allgower R, Matuschka FR. Relationships of a novel Lyme disease spirochete, Borrelia spielmani sp nov., with its hosts in central Europe. Appl Environ Microbiol. 2004;70(11):6414-9.

106. Schmidt S, Essbauer SS, Mayer-Scholl A, Poppert S, Schmidt-Chanasit J, Klempa $B$, et al. Multiple infections of rodents with zoonotic pathogens in Austria. Vector Borne Zoonotic Dis. 2014;14(7):467-75.

107. Zore A, Petrovec M, Prosenc K, Trilar T, Ruzic-Sabljic E, Avsic-Zupanc T. Infection of small mammals with Borrelia burgdorferi sensu lato in Slovenia as determined by polymerase chain reaction (PCR). Wien Klin Wochenschr. 1999;111(22-23):997-9.

108. Jaenson TGT, Talleklint L. Incompetence of roe deer as reservoirs of the Lyme borreliosis spirochete. J Med Entomol. 1992;29(5):813-7.

109. Pacilly FC, Benning ME, Jacobs F, Leidekker J, Sprong H, Van Wieren SE, et al. Blood feeding on large grazers affects the transmission of Borrelia burgdorferi sensu lato by Ixodes ricinus. Ticks Tick Borne Dis. 2014;5(6): 810-7.

110. Brunner JL, Logiudice K, Ostfeld RS. Estimating reservoir competence of borrelia burgdorferi hosts: Prevalence and infectivity, sensitivity, and specificity. J Med Entomol. 2008;45(1):139-47.
111. Tälleklint $L$, Jaenson TGT. Transmission of Borrelia burgdorferi s.l. from mammal reservoirs to the primary vector of lyme borreliosis, Ixodes ricinus (Acari: Ixodidae), in Sweden. J Med Entomol. 1994;31(6):880-6.

112. Tschirren B, Andersson M, Scherman K, Westerdahl H, Mittl PRE, Raberg L: Polymorphisms at the innate immune receptor TLR2 are associated with Borrelia infection in a wild rodent population. Proc R Soc Biol Sci Ser B. 2013;280(1759):20130364.

113. Gern L, Siegenthaler M, Hu CM, Leuba-Garcia S, Humair PF, Moret J. Borrelia burgdorferi in rodents (Apodemus flavicollis and A. sylvaticus): Duration and enhancement of infectivity for Ixodes ricinus ticks. Eur J Epidemiol. 1994; 10(1):75-80.

114. Perez D, Kneubuhler $Y$, Rais $O$, Gern L. Seasonality of Ixodes ricinus ticks on vegetation and on rodents and Borrelia burgdorferi sensu lato genospecies diversity in two Lyme borreliosis-endemic areas in Switzerland. Vector Borne Zoonotic Dis. 2012;12(8):633-44.

115. Radzijevskaja J, Paulauskas A, Rosef O, Petkevicius S, Mazeika V, Rekasius T. The propensity of voles and mice to transmit Borrelia burgdorferi sensu lato infection to feeding ticks. Vet Parasitol. 2013;197(1-2):318-25.

116. Kurtenbach K, Dizij A, Seitz HM, Margos G, Moter SE, Kramer MD, et al. Differential immune-responses to Borrelia burgdorferi in European wild rodent species influence spirochete transmission to Ixodes ricinus $L$ (Acari, Ixodidae). Infect Immun. 1994;62(12):5344-52.

117. Richter D, Klug B, Spielman A, Matuschka FR. Adaptation of diverse Lyme disease spirochetes in a natural rodent reservoir host. Infect Immun. 2004; 72(4):2442-4.

118. Barbour AG, Bunikis J, Fish D, Hanincova K. Association between body size and reservoir competence of mammals bearing Borrelia burgdorferi at an endemic site in the northeastern United States. Parasit Vectors. 2015;8(1):299.

119. Heylen D, Matthysen E, Fonville M, Sprong H. Songbirds as general transmitters but selective amplifiers of Borrelia burgdorferi sensu lato genotypes in Ixodes rinicus ticks. Environ Microbiol. 2013;16(9):2859-68.

120. Richter D, Debski A, Hubalek Z, Matuschka FR. Absence of Lyme disease spirochetes in larval Ixodes ricinus ticks. Vector Borne Zoonotic Dis. 2012; 12(1):21-7.

121. Johns R, Ohnishi J, Broadwater A, Sonenshine DE, De Silva AM, Hynes WL. Contrasts in tick innate immune responses to Borrelia burgdorferi challenge: immunotolerance in Ixodes scapularis versus immunocompetence in Dermacentor variabilis (Acari: Ixodidae). J Med Entomol. 2001;38(1):99-107.

122. Hovius JW, Li X, Ramamoorthi N, van Dam AP, Barthold SW, van der Poll T, et al. Coinfection with Borrelia burgdorferi sensu stricto and Borrelia garinii alters the course of murine Lyme borreliosis. FEMS Immunol Med Microbiol. 2007:49(2):224-34

123. Lindsay LR, Barker IK, Surgeoner GA, McEwen SA, Campbell GD. Duration of Borrelia burgdorferi infectivity in white-footed mice for the tick vector Ixodes scapularis under laboratory and field conditions in Ontario. J Wildl Dis. 1997:33(4):766-75.

124. Tonetti N, Voordouw MJ, Durand J, Monnier S, Gern L: Genetic variation in transmission success of the Lyme borreliosis pathogen Borrelia afzelii. Ticks Tick Borne Dis 2015(0)

125. Kurtenbach K, De Michelis S, Sewell HS, Etti S, Schafer SM, Holmes E, et al. The key roles of selection and migration in the ecology of Lyme borreliosis. Int J Med Microbiol. 2002:291 Suppl 33:152-4.

126. Kurtenbach K, Sewell HS, Ogden NH, Randolph SE, Nuttall PA. Serum complement sensitivity as a key factor in Lyme disease ecology. Infect Immun. 1998;66(3):1248-51.

127. Jacquot M, Bisseux M, Abrial D, Marsot M, Ferquel E, Chapuis $J$, et al. High-throughput sequence typing reveals genetic differentiation and host specialization among populations of the Borrelia burgdorferi species complex that infect rodents. PLoS One. 2014;9(2):e88581.

128. Mather TN, Telford SR, Adler GH. Absence of transplacental transmission of Lyme disease spirochetes from reservoir mice (Peromyscus leucopus) to their offspring. J Infect Dis. 1991;164(3):564-7.

129. Wright SD, Nielsen SW. Experimental infection of the white-footed mouse with Borrelia burgdorferi. Am J Vet Res. 1990;51(12):1980-7.

130. Gern L, Lebet N, Moret J. Dynamics of Borrelia burgdorferi infection in nymphal Ixodes ricinus ticks during feeding. Exp Appl Acarol. 1996;20(11): 649-58.

131. Gern LZ L, Aeschlimann A. Development of Borrelia burgdorferi in Ixodes ricinus females during blood feeding. Ann Parasitol Hum Comp. 1990;62(2):5. 
132. Crippa M, Rais O, Gern L. Investigations on the mode and dynamics of transmission and infectivity of Borrelia burgdorferi sensu stricto and Borrelia afzelii in Ixodes ricinus ticks. Vector Borne Zoonotic Dis. 2002;2(1):3-9.

133. Cook MJ. Lyme borreliosis: A review of data on transmission time after tick attachment. Int J Gen Med. 2015;8:1-8.

134. Kahl O, Janetzki-Mittmann C, Gray JS, Jonas R, Stein J, De Boer R. Risk of infection with Borrelia burgdorferi sensu lato for a host in relation to the duration of nymphal Ixodes ricinus feeding and the method of tick removal. Zentralbl Bakteriol. 1998;287(1-2):41-52.

135. Leuba-Garcia S, Kramer MD, Wallich R, Gern L. Characterization of Borrelia burgdorferi isolated from different organs of Ixodes ricinus ticks collected in nature. Zentralbl Bakteriol. 1994;280(4):468-75.

136. Shih CM, Pollack RJ, Telford 3rd SR, Spielman A. Delayed dissemination of Lyme disease spirochetes from the site of deposition in the skin of mice. J Infect Dis. 1992;166(4):827-31.

137. Sinsky RJ, Piesman J. Ear punch biopsy method for detection and isolation of Borrelia burgdorferi from rodents. J Clin Microbiol. 1989;27(8):1723-7.

138. Callister SM, Agger WA, Schell RF, Brand KM. Efficacy of the urinary bladder for isolation of Borrelia burgdorferi from naturally infected, wild Peromyscus leucopus. J Clin Microbiol. 1989;27(4):773-4.

139. Hofmeister EK, Markham RB, Childs JE, Arthur RR. Comparison of polymerase chain-reaction and culture for detection of Borrelia-burgdorferi in naturally infected Peromyscus-leucopus and experimentally infected C.B-17 scid scid mice. J Clin Microbiol. 1992;30(10):2625-31.

140. Snydman DR, Schenkein DP, Berardi VP, Lastavica CC, Pariser KM. Borrelia burgdorferi in joint fluid in chronic Lyme arthritis. Ann Intern Med. 1986; 104(6):798-800.

141. Richter D, Matuschka FR. Perpetuation of the Lyme disease spirochete Borrelia lusitaniae by lizards. Appl Environ Microbiol. 2006;72(7):4627-32.

142. Richter D, Schlee DB, Matuschka FR. Reservoir competence of various rodents for the Lyme disease spirochete Borrelia spielmanii. Appl Environ Microbiol. 2011;77(11):3565-70

143. Matuschka FR, Spielman A. Loss of Lyme disease spirochetes from Ixodes ricinus ticks feeding on European blackbirds. Exp Parasitol. 1992;74(2):151-8.

144. Kurtenbach K, Schäfer SM, Sewell HS, Peacey M, Hoodless A, Nuttall PA, et al. Differential survival of lyme borreliosis spirochetes in ticks that feed on birds. Infect Immun. 2002;70(10):5893-5.

145. Nazario S, Das S, de Silva AM, Deponte K, Marcantonio N, Anderson JF, et al. Prevention of Borrelia burgdorferi transmission in quinea pigs by tick immunity. Am J Trop Med Hyg. 1998;58(6):780-5.

146. Wikel SK, Ramachandra RN, Bergman DK, Burkot TR, Piesman J. Infestation with pathogen-free nymphs of the tick Ixodes scapularis induces host resistance to transmission of Borrelia burgdorferi by ticks. Infect Immun. 1997:65(1):335-8.

147. Hofmeister EK, Ellis BA, Glass GE, Childs JE. Longitudinal study of infection with Borrelia burgdorferi in a population of Peromyscus leucopus at a Lyme disease-enzootic site in Maryland. Am J Trop Med Hyg. 1999;60(4):598-609.

148. Shih CM, Spielman A. Accelerated transmission of Lyme disease spirochetes by partially fed vector ticks. J Clin Microbiol. 1993;31(11):2878-81.

149. Piesman J. Experimental acquisition of the Lyme disease spirochete, Borrelia burgdorferi, by larval Ixodes dammini (Acari: Ixodidae) during partial blood meals. J Med Entomol. 1991;28(2):259-62.

150. Pichon B, Godfroid E, Hoyois B, Bollen A, Rodhain F, Perez-Eid C. Simultaneous infection of Ixodes ricinus nymphs by two Borrelia burgdorferi sensu lato species: possible implications for clinical manifestations. Emerging Infect Dis. 1995;1(3):89-90.

151. Misonne MC, Van Impe G, Hoet PP. Genetic heterogeneity of Borrelia burgdorferi sensu lato in Ixodes ricinus ticks collected in Belgium. J Clin Microbiol. 1998:36(11):3352-4.

152. Herrmann C, Gern L, Voordouw MJ. Species co-occurrence patterns among lyme borreliosis pathogens in the tick vector Ixodes ricinus. Appl Environ Microbiol. 2013;79(23):7273-80

153. Dunham-Ems SM, Caimano MJ, Pal U, Wolgemuth CW, Eggers $\mathrm{CH}$, Balic A, et al. Live imaging reveals a biphasic mode of dissemination of Borrelia burgdorferi within ticks. J Clin Invest. 2009;119(12):3652-65.

154. Barthold SW. Infectivity of Borrelia burgdorferi relative to route of inoculation and genotype in laboratory mice. J Infect Dis. 1991;163(2):419-20.

155. Randolph SE, Craine NG. General framework for comparative quantitative studies on transmission of tick-borne diseases using lyme borreliosis in Europe as an example. J Med Entomol. 1995:32(6):765-77.

\section{Submit your next manuscript to BioMed Central and we will help you at every step:}

- We accept pre-submission inquiries

- Our selector tool helps you to find the most relevant journal

- We provide round the clock customer support

- Convenient online submission

- Thorough peer review

- Inclusion in PubMed and all major indexing services

- Maximum visibility for your research

Submit your manuscript at www.biomedcentral.com/submit 